\title{
Shale Gas Pseudo Two-Dimensional Unsteady Seepage Pressure Simulation Analysis in Capillary Model
}

\author{
Lai Fengpeng $^{1 *}$, Li Zhiping ${ }^{1}$, Li Zhifeng ${ }^{2}$, Yang Zhihao ${ }^{1}$ and Fu Yingkun ${ }^{1}$ \\ 1 School of Energy Resources, China University of Geosciences, Beijing 100083 - China \\ 2 China Huadian Engineering Co., Ltd, Beijing 100035 - China \\ e-mail: laifengpeng@cugb.edu.cn \\ * Corresponding author
}

\begin{abstract}
Shale gas is rapidly growing as a source of natural gas in China. Compared with the conventional gas reservoir, the shale gas reservoir is characterized by low porosity, low permeability, and adsorbed gas, making the flow mechanism of shale gas reservoir more complex. In this study, we investigated six factors influencing the gas flow: the Darcy flow, the slippage effect, the Knudsen diffusion effect, the desorption of gas on pore walls, the diffusion effect of gas in organic matter, and the matrix deformation effect. We simplified gas flow in the development process to only include gas flow in the capillaries and then considered the six influence factors. This study establishes a shale gas pseudo two-dimensional unsteady capillary seepage mathematical model based on the continuity equation, using the implicit difference method to solve the mathematical model. Certain capillary parameters were added to the calculation, and the study analyzed the effect of the different factors on both the pressure distribution and the cumulative gas production. Results show that the Knudsen diffusion effect and the desorption of gas from pore walls have lower impact on the pressure than the others factors. The diffusion effect of gas in organic matter, the slippage effect, and the matrix deformation effect have a stronger impact on the pressure. The gas in organic matter continuously diffuses into the capillary with the increasing of the production time, and the pressure drop becomes slow because of the gas diffusion.
\end{abstract}

Résumé - Analyse des instabilités d'une simulation pseudo-bidimensionnelle de la pression de filtration de gaz de schiste dans un modèle capillaire - Le gaz de schiste connaît une croissance rapide en tant que source de gaz naturel en Chine. En comparaison du réservoir de gaz conventionnel, le réservoir de gaz de schiste se caractérise par une faible porosité, une faible perméabilité, et par le gaz adsorbé qui rend le mécanisme d'écoulement du réservoir de gaz de schiste plus complexe. Dans cette étude, nous avons étudié six facteurs qui influencent le débit de gaz : l'écoulement selon le modèle de Darcy, l'effet de glissement, l'effet de diffusion Knudsen, la désorption du gaz sur les parois poreuses, l'effet de diffusion du gaz dans la matière organique et l'effet de déformation de la matrice. Nous avons simplifié le débit de gaz dans un modèle pour inclure uniquement le débit de gaz dans les capillaires et ensuite étudier les six facteurs d'influence. Cette étude développe un modèle mathématique de pénétration capillaire instable et pseudo-bidimensionnelle du gaz de schiste en se fondant sur l'équation de continuité et en utilisant la méthode de différence implicite pour résoudre le modèle mathématique. 
Certains paramètres des capillaires ont été ajoutés au calcul et l'étude a analysé l'effet des différents facteurs sur la distribution de pression et sur la production cumulée de gaz. Les résultats montrent que l'effet Knudsen et la désorption du gaz à partir de parois poreuses ont un impact moins important sur la pression que les autres facteurs. L'effet de diffusion du gaz dans une matière organique, l'effet de glissement et la déformation de la matrice ont une plus grande influence sur la pression. Le gaz dans la matière organique diffuse en continu dans le capillaire au fur et à mesure de la production, et la baisse de pression est ralentie à cause de la diffusion du gaz.

\section{INTRODUCTION}

In shale-gas systems, nanometer- to micrometer-size pores, along with natural fractures, form the flow-path network that allows flow of gas from the mud rock to induced fractures during production (Loucks et al., 2012). Shale gas production involves many different stages, such as reservoir and well bore. The production of a new drilling well comes first from a fracture and macro pore, and then from a small pore. The thermodynamic equilibrium between the gas and organic/clay changes as the gas is desorbed from the surface of the organic/clay during the development process. Driven by the changing thermodynamic equilibrium, the gas molecules diffuse from within the organic matter to its outer surface and then into the pore network. The gas flowing model that considers pore size has been applied to shale gas reservoir; it considers the change in the state of gas molecules according to Darcy's law. The Klinkenberg slippage effect contributes to the analysis of the production increase of tight gas and shale gas reservoirs (Ertekin et al., 1986). A comprehensive slippage concept is used to modify Darcy's law (Clarkson et al., 2012). In addition to Darcy's law, the concentration difference diffusion also influences gas flow (Ozkan et al., 2010). The contributions of slip flow and Knudsen diffusion increase the apparent permeability of the reservoir while gas production takes place. The effects of both mechanisms explain the higher-than-expected gas production rates commonly observed in these formations (Shabro et al., 2011).

Shale gas reserves have been exploited in Sichuan and Bohai bay basins in China. However, the study of the percolation mechanism and the capacity evaluation of shale gas is still in its infancy. A very high proportion of shale gas research has been focused towards understanding and improving the hydraulic fracturing in shale gas and comparatively less work has been done towards understanding the flow mechanism in the shale matrix (Swami and Settari, 2012). The CoalBed Methane (CBM) model is typically used to simulate the production characteristics of shale gas since shale undergoes organic carbon adsorption. Conventional Darcy seepage models are also used to describe the production characteristics of shale gas. Darcy's law is modified by introducing apparent permeability to obtain the constitutive equation for gas seepage (Yao et al., 2012). However, these models are not based on shale's nanometer pore structure, which can cause some deviations in the description of its percolation mechanism, leading to incorrect reservoir evaluations and prediction.

In this paper, we first study the impact of the factors influencing gas flow and establish a capillary model to simplify the shale gas flow development process. The factors include Darcy flow, Knudsen diffusion, slippage effect, the desorption effect of adsorbed gas on pore wall surface, the diffusion effect of organic matter gas and matrix deformation effect. Based on the continuity equation, we deduce a shale gas pseudo two-dimensional unsteady capillary seepage mathematical model and use the implicit difference method to solve the mathematical model. Finally, we suggest some parameter values for the capillary model and analyze the impact of different factors influencing the pressure distribution.

\section{SHALE GAS FLOW MECHANISM IN CAPILLARY}

Several studies have proposed flow models capturing pore scale flow mechanism in shale reservoirs. Probably the simplest models from which Darcy's law may be derived are those made of capillary tubes in one arrangement or another. The starting point in all these models is Hagen-Poisseuille's law governing the steady flow through a single, straight circular capillary tube. Other models based on capillary tubes are described (Bear, 1972; Kanellopoulos, 1985). Ertekin et al. (1986) incorporated Klinkenberg's slippage effect to account for the higher than predicted value of production in shale reservoirs. Javadpour (2009) stated that both slippage and Knudsen diffusion become important at the shale nano pore scale.

\subsection{Influence Factor Analysis of Gas Flow}

\subsubsection{Darcy Flow}

While shale gas reservoir is different from conventional natural gas reservoir, the Darcy seepage law is used in 
both to describe the relationship between the gas flow and pressure in microscopic pores.

\subsubsection{Slippage Effect}

Gas slippage effect was the first time found by Kundt and Warburg (Scheidegger, 1957). Muskat (1946) applied gas flow in porous media theory to the development of oil and gas fields, making the gas slippage effect theoretical research possible for low permeability gas reservoirs industrialized mining. Compared to the rocks in conventional reservoirs, gas shales generally have much smaller pores and pore throats. Therefore, in gas shale, collisions between molecules and pore walls are more frequent than collisions between the molecules themselves. Under these circumstances, the process of gas slippage becomes important, resulting in matrix permeability that is dependent upon the type of gas flowing through the shale as well as the gas pressure (Letham, 2011).

\subsubsection{Knudsen Diffusion Effect}

Gas diffusion can be described by superposition of viscous and Knudsen flow (Markovic et al., 2009), and the phenomena of gas diffusion through porous materials has been discussed extensively by Kerkhof and Geboers (2005). Knudsen diffusion occurs when the scale length of a system is comparable to or smaller than the mean free path of the particles involved, e.g. in a long pore with a narrow diameter $(2-50 \mathrm{~nm})$, because molecules frequently collide with the pore wall (Malek and Coppens, 2003). In the Knudsen diffusion regime, the molecules do not interact with one another, but move in straight lines between points on the pore channel surface.

\subsubsection{Desorption Effect of Adsorbed Gas on Pore Wall Surface}

The impact of the adsorption layer on gas flowing in the pores is worth considering. Hartman et al. (2011) extend their discussion to the adsorption layer effect on multicomponent natural gases. Their approach is based on the thermodynamically consistent ideal adsorbed solution model to accurately predict adsorbed gas storage capacity for gas mixtures. Swami (2012) postulates that a significant amount of gas is also stored in the bulk of organic matter or kerogen. In his conceptual model of one shale pore, he models flow behavior taking into account the free gas, adsorbed gas, and gas dissolved in kerogen, and found that after the reservoir pressure becomes less than the critical pressure, gas adsorption capacity decreases as reservoir pressure decreases.

\subsubsection{Diffusion Effect of Organic Matter Gas}

There is a lot of adsorbed gas in shale, with an adsorbed gas portion ranging anywhere from $20 \%$ to $85 \%$ (Curtis, 2002). Much of the shale gas in organic matter is in the adsorbed state. When reservoir pressure decreases, shale gas spreads from organic matter into nanoscale pores and then diffuses by percolation. The diffusion rate of gas in organic matter is slow and the diffusion amount is small, so the production period of a shale gas well can reach up to several decades. Fick's laws can be used to describe the flow caused by a change in concentration of adsorbed gas due to pressure changes.

\subsubsection{Matrix Deformation Effect}

The effective stress in a shale reservoir increases with reservoir pressure, thus reducing the rate of the development process. When a reservoir is compacted, its physical properties such as porosity and permeability decrease. However, when reservoir pressure becomes lower than the critical desorption pressure, shale gas desorbs from the adsorption layer, which causes matrix shrinkage, and an improvement in the reservoir's physical properties.

\subsection{Shale Gas Flow Mechanism}

In the shale gas development process, gas mainly comes from within and outside of the reservoir's organic matter, diffuses into the large pores and fractures and eventually flows into the well bore. In this paper, we use the capillary flow model to simplify the whole flow process and consider the factors influencing gas flow identified above.

During the simulation of gas flow in the capillaries, the reduction of pressure causes free gas to flow, according to Darcy's flow and also results in the gas molecules slippage effect. Gas molecules in the capillary wall are in motion, so Knudsen diffusion should be considered because capillary size is nanoscale. The adsorbed gas in the capillary wall is desorbed as pressure continues to decline. The adsorbed gas in organic matter that is outside the capillary walls begins to diffuse into the capillaries, and this diffusion causes an increase of the pressure. The gas flowing into the capillaries is affected by the six factors listed above.

Shale gas in reservoirs has three kinds of storage forms according to flow law. The first is free gas in pores, the second is adsorbed gas on the surface of pore walls, and the last is adsorbed gas in organic matter. The flow process of these three forms of gas is controlled by six mechanisms as described above. 


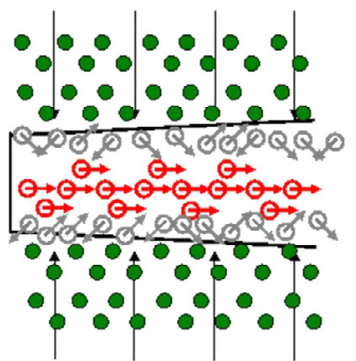

Profile schematic diagram

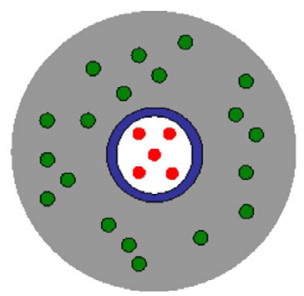

Cross-section schematic diagram
Figure 1

Capillary gas flow diagram.

\section{SHALE GAS FLOW MODEL IN CAPILLARY}

\subsection{Model Assumes}

\subsubsection{Assumptions}

1) The capillary model is composed of a matrix pore system and a large number of organic inclusions;

2) Flow in the reservoir is isothermal, free gas is the real gas;

3) The diffusion of gas from organic inclusions flows radially, the diffusion of gas from the capillaries flows linearly;

4) In the initial state, a certain amount of free gas stays in the capillaries, and most of the gas stays on the inner surface of the matrix and in the adsorbed state in organic matter;

5) The flow in the capillaries reflects a multi-flow mechanism, without regard to gravity or the pressure effects;

6) Radial flow reflects a process of diffusion, and this gas diffusion process is in a non-equilibrium pseudosteady state, according to Fick's first law.

\subsubsection{Schematic Diagram}

The shale nanoscale pore flow channel is assumed to be a two-dimensional cylindrical flow pipe, with a volume of organic matter outside the cylindrical pipe (Fig. 1). A large volume of gas absorbed on the organic matter desorbs with the change of reservoir pressure, then diffusing from organic matter block into the pore through pore wall (green point shown in Fig. 1). Meanwhile, gas adsorbed on the surface of pore begins its desorption, then directly flowing into the pore channels (grey point shown in Fig. 1). The free gas now flows in the pore channel under pressure difference (red point shown in Fig. 1).

There is a closed boundary at one end of the cylindrical pipe, the initial pressure is $P_{i}$, the pressure at the drain tunnel is $P_{w}$, and there is a layer of gas molecules adsorbed on the surface of pore wall. During the reduction of pore pressure, the adsorbed gas in the organic matter is desorbed, and then diffuses into the pores through surface contact between the organic matter and the pore.

\subsection{Capillary Gas Flow Models}

\subsubsection{Darcy Seepage Equation}

Considering Darcy seepage, both the motion equation and the ideal gas state equation are considered in the continuity equation, and the quality basic differential equation can be described as follows:

$$
\frac{M}{2 R T} \frac{K_{m}}{z \mu_{g}} \frac{\partial}{\partial x}\left(\frac{d p^{2}}{d x}\right)=\frac{M}{R T z} C_{g} \frac{\partial p^{2}}{\partial t}
$$

where $M$ is the molecular mass in $\mathrm{g} / \mathrm{mol}, K_{m}$ is the permeability in $\mathrm{mD}, R$ is the universal gas constant, $T$ is the temperature in $\mathrm{K}, z$ is the gas compressibility factor, $\mu_{g}$ is the gas viscosity in mPa.s, $x$ is the capillary position in $\mathrm{cm}, C_{g}$ is the gas compressibility in $\mathrm{MPa}^{-1}, p$ is the pressure in $\mathrm{MPa}$, and $t$ is the time in $\mathrm{s}$.

\subsubsection{Desorption Effect of the Pore Wall Adsorbed Gas}

The Langmuir equation can be used to describe the phenomenon of the CBM adsorbed on the coal seam surface, and is also used in the study of shale gas reservoirs because shale gas is similar to CBM. In the Langmuir isotherm equation, the relationship between gas pressure and gas adsorption can be expressed as follows:

$$
V=V_{L} \frac{b p}{1+b p}
$$

where $V$ is the gas adsorption in $\mathrm{m}^{3} / \mathrm{t}, V_{L}$ is the gas Langmuir volume in $\mathrm{m}^{3} / \mathrm{t}$, and $b$ is the gas Langmuir adsorption constant in $\mathrm{MPa}^{-1}$.

As the pressure decreases, gas flows into the well bore from the pore walls, and the gas flow equation at the time of resolution on the wall can be described as in Equation (3):

$$
J_{d}=\rho_{r} \rho_{g} V \frac{b}{(1+b p)^{2}} \frac{\partial p}{\partial t}
$$

where $\rho_{r}$ is the shale density in $\mathrm{kg} / \mathrm{m}^{3}$, and $\rho_{g}$ is the methane gas density in $\mathrm{kg} / \mathrm{m}^{3}$.

\subsubsection{Diffusion Effect of the Gas in Organic Matter}

A large amount of shale gas is adsorbed given large amounts of organic matter outside of the capillaries. 
Gas desorbs from the organic matter when the pressure drops below the critical desorption pressure, and gas flows into the capillary by concentration diffusion.

Given the outer radius of the enfolded peripheral cylinder $r$, the flow equation of gas diffusion from the organic system to the inner capillaries can be described as in Equation (4):

$$
J_{k}=\frac{\rho_{r} \pi r^{2} L \rho_{g}\left(V_{L}-\overline{V_{i}}\right) D_{k}}{\pi\left(\frac{d}{2}\right)^{2}}
$$

where $L$ is the core length in $\mathrm{m}, \bar{V}_{i}$ is the equilibrium adsorption quantity in $\mathrm{m}^{3} / \mathrm{t}, d$ is the nano pore current diameter in $\mathrm{m}$ and $D_{k}$ is the diffusion coefficient of organic matter in $\mathrm{m}^{2} / \mathrm{s}$.

\subsubsection{Matrix Deformation Effect}

The nano pore diameter changing equation, which considers matrix shrinkage and stress sensitivity can be described as in Equation (5):

$$
\begin{gathered}
d=d_{i}\left(1+\left(1+\frac{2}{\phi_{i}}\right)\right. \\
\left.\left\{\frac{V_{L} \rho_{r} R T}{E V_{0}}\left[\ln \left(1+b p_{i}\right)-\ln (1+b p)\right]+C_{p}\left(p_{i}-p\right)\right\}\right)^{0.5}
\end{gathered}
$$

where $d_{i}$ is the original diameter of nano pore in $\mathrm{m}, \phi_{i}$ is the original porosity in fractional, $p_{i}$ is the initial pressure in $\mathrm{MPa}, p$ is the currently reservoir pressure in $\mathrm{MPa}, C_{p}$ is the elastic compression factor in $10^{-4} \mathrm{MPa}^{-1}, E$ is the Young's modulus in $\mathrm{MPa}$, and $V_{0}$ is the gas molar volume in $10^{-3} \mathrm{~m}^{3} / \mathrm{mol}$.

\section{UNSTEADY FLOW MODELS OF SHALE GAS CAPILLARY MODEL}

Since the gas flow in the capillary is influenced by the six factors identified above, the continuity equation can be described as follows:

$$
\begin{gathered}
\frac{M}{2 R T} \frac{C_{g} D \mu_{g}+F K_{m}}{z \mu_{g}} \frac{\partial}{\partial x}\left(\frac{d p^{2}}{d x}\right)- \\
\rho_{r} \rho_{g} V_{L} \frac{b}{(1+b p)^{2}} \frac{\partial p}{\partial t}+\frac{\rho_{r} \rho_{g}\left(\frac{b p_{L}}{1+b p_{L}}-\frac{b p}{1+b p}\right) D_{k}}{\pi\left(\frac{d}{2}\right)^{2}}=\frac{M}{R T z} C_{g} \frac{\partial p^{2}}{\partial t}
\end{gathered}
$$

where $D$ is Knudsen diffusion constant in $\mathrm{m}^{2} / \mathrm{s}$, and $p_{L}$ is the Langmuir pressure in $\mathrm{MPa}$.

$$
D=\frac{d}{3} \sqrt{\frac{8 R T}{\pi M}}
$$

The gas molecule near the capillary wall flows more easily because of the slippage effect. The dimensionless slippage factor $F$ is used to modify the slip velocity in capillary tubes (Brown et al., 1946; Swami and Settari, 2012). The factor $F$ may be looked upon as the ratio of $\mu_{g}$ to the effective viscosity applicable to Poiseuille's equation at low pressures (Brown et al., 1946):

$$
F=1+1000\left(\frac{8 \pi R T}{M}\right)^{0.5} \frac{\mu_{g}}{\bar{p} r}\left(\frac{2}{\alpha}-1\right)
$$

where $\bar{p}$ is the average pressure in MPa, $r$ is the nano pore radius in $\mathrm{m}$, and $\alpha$ is the dimensionless distribution coefficient of diffusion flow.

$K_{m}$ is the Darcy permeability and is given by Poiseuille equation for circular capillaries as:

$$
k_{m}=\frac{r^{2}}{8}=\frac{d^{2}}{32}
$$

Equation (5), (7), (8) and Equation (9) are put into Equation (6), and the resulting equation is as follows: see Equation (10) below

$$
\begin{gathered}
\frac{M}{2 R T} \frac{C_{g} d_{i}\left(1+\left(1+\frac{2}{\phi_{i}}\right)\left\{\frac{V_{L} \rho_{r} R T}{E V_{0}}\left[\ln \left(1+b p_{i}\right)-\ln (1+b p)\right]+C_{p}\left(p_{i}-p\right)\right\}\right)^{0.5} \sqrt{\frac{8 R T}{9 \pi M}} \mu_{g}}{z \mu_{g}} \frac{\partial}{\partial x}\left(\frac{d p^{2}}{d x}\right) \\
+\frac{M}{2 R T} \frac{F d_{i}^{2}\left(1+\left(1+\frac{2}{\phi_{i}}\right)\left\{\frac{V_{L} \rho_{r} R T}{E V_{0}}\left[\ln \left(1+b p_{i}\right)-\ln (1+b p)\right]+C_{p}\left(p_{i}-p\right)\right\}\right)}{32 z \mu_{g}} \frac{\partial}{\partial x}\left(\frac{d p^{2}}{d x}\right)-\rho_{r} \rho_{g} V_{L} \frac{b}{(1+b p)^{2}} \frac{\partial p}{\partial t} \\
+\frac{\rho_{r} \rho_{g}\left(\frac{b p_{L}}{1+b p_{L}}-\frac{b p}{1+b p}\right) D_{k}}{\pi}=\frac{M}{R T z} C_{g} \frac{\partial p^{2}}{\partial t} \\
\pi \frac{d_{i}^{2}\left(1+\left(1+\frac{2}{\phi_{i}}\right)\left\{\frac{V_{L} \rho_{r} R T}{E V_{0}}\left[\ln \left(1+b p_{i}\right)-\ln (1+b p)\right]+C_{p}\left(p_{i}-p\right)\right\}\right)}{4}
\end{gathered}
$$


The initial condition for Equation (10) can be described as follows:

$$
t=0, P=P_{i}, 0 \leq x<L
$$

The inner boundary condition for Equation (9) can be described as follows:

$$
x=0, P=P_{w}, t>0
$$

The outer boundary condition for Equation (9) can be represented as:

$$
x=L, \frac{\partial p}{\partial x}=0, t>0
$$

\section{SHALE GAS UNSTEADY FLOW SIMULATION ANALYSIS}

To emulate gas flow, we represent a nanopore by a capillary tube. Figure 1 shows the physical model. The entire system is at initial reservoir pressure in the beginning. Right boundary of the pore is open to a constant pressure, and the left boundary is a no flow boundary. Shabro et al. (2011) and Swami and Settari (2012) listed some data in their papers. We referred to these data, but did not copy the data. For example, the pore radius is $2 \mathrm{~nm}$ in their papers, we assume the radius is $1 \mathrm{~nm}$. We compare some data in Table 1.

Table 2 shows the simulation-related parameters and values for this simulation model. Results from this model are used to analyze the impact of the six factors influencing pressure and gas production.

The radial flow of gas from the organic matter to the capillaries also flows along the capillary strings at the same time. We use the implicit method to solve the flow process. Following the gas seepage model for the capillaries, we first study the pressure distribution in the capillaries. Figure 2 shows the nonlinear pressure distribution from the closed boundary to the constant

TABLE 1

\begin{tabular}{l|c|c|c}
\hline \multicolumn{4}{c}{ Comparison of some data } \\
\hline Parameter & $\begin{array}{c}\text { Value in } \\
\text { this paper }\end{array}$ & $\begin{array}{c}\text { Value in the } \\
\text { reference }\end{array}$ & Units \\
\hline Nano pore radius & 1 & 2 & $\mathrm{~nm}$ \\
\hline Nano pore length & 1 & $1 \times 10^{-7}$ to 1 & $\mathrm{~m}$ \\
\hline Langmuir volume & 0.035 & 0.02 & $\mathrm{~m}^{3} / \mathrm{kg}$ \\
\hline $\begin{array}{l}\text { Inner boundary } \\
\text { pressure }\end{array}$ & 5 & 8.6 & $\mathrm{MPa}$ \\
\hline $\begin{array}{l}\text { Outer boundary } \\
\text { pressure }\end{array}$ & 25 & 17.2 & $\mathrm{MPa}$ \\
\hline Rock density & 2560 & 2500 & $\mathrm{~kg} / \mathrm{m}^{3}$ \\
\hline
\end{tabular}

pressure drainage boundary, which is calculated with consideration to the six factors identified above.

The pressure drops slowly near the closed boundary, indicating that the drop in pressure is smaller at the closed boundary than at the drainage boundary. As the pressure reduces, there is greater influence from the six factors.

Figure 3 shows the pressure distribution under the influence of different factors. Figure 4 shows the simulation pressure when considering these six factors, and the pressure result when not considering the matrix deformation effect. In Figure 4, the pressure at the closed

TABLE 2

Simulation related parameters and value

\begin{tabular}{l|c|c}
\hline Parameter & Value & Units \\
\hline Nano pore radius & 1 & $\mathrm{~nm}$ \\
\hline Nano pore length & 1 & $\mathrm{~m}$ \\
\hline Reservoir temperature & 60 & ${ }^{\circ} \mathrm{C}$ \\
\hline Gas viscosity & 0.015 & $\mathrm{mPa} \cdot \mathrm{s}$ \\
\hline Knudsen diffusion coefficient & $2 \mathrm{E}-11$ & $\mathrm{~m}^{2} / \mathrm{s}$ \\
\hline Outer boundary pressure & 25 & $\mathrm{MPa}$ \\
\hline Inner boundary pressure & 5 & $\mathrm{MPa}$ \\
\hline Langmuir constant & 0.4 & $\mathrm{MPa}{ }^{-1}$ \\
\hline Langmuir volume & 0.035 & $\mathrm{~m}^{3} / \mathrm{kg}$ \\
\hline Inclusions radius & 0.0000001 & $\mathrm{~m}$ \\
\hline Gas density & 0.7174 & $\mathrm{~g} / \mathrm{L}$ \\
\hline Rock density & 2560 & $\mathrm{~kg} / \mathrm{m}^{3}$ \\
\hline
\end{tabular}

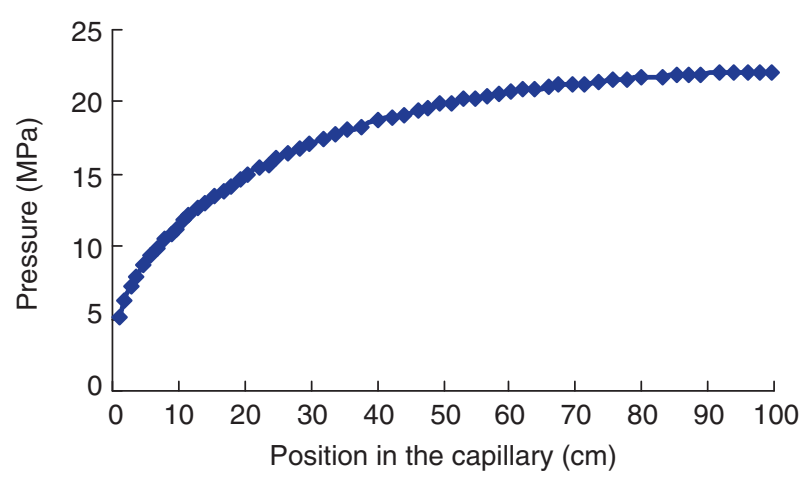

Figure 2

Pressure distribution at different position in the capillary. 


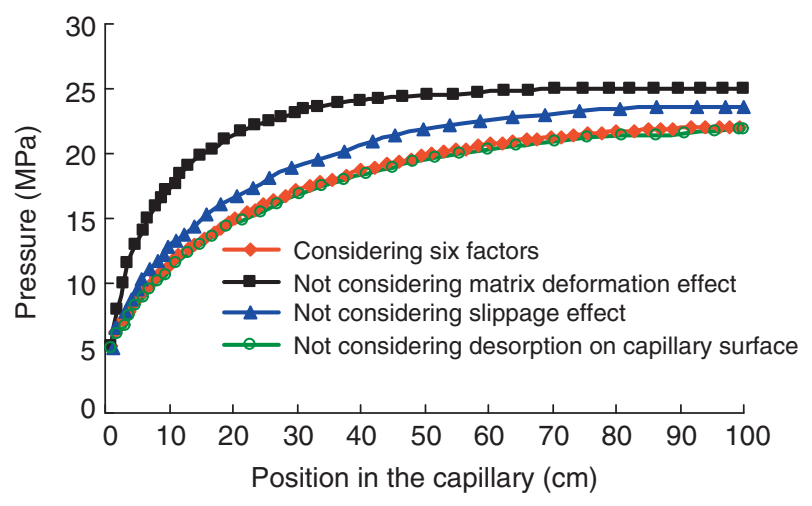

Figure 3

Capillary pressure distribution under different influence factors.

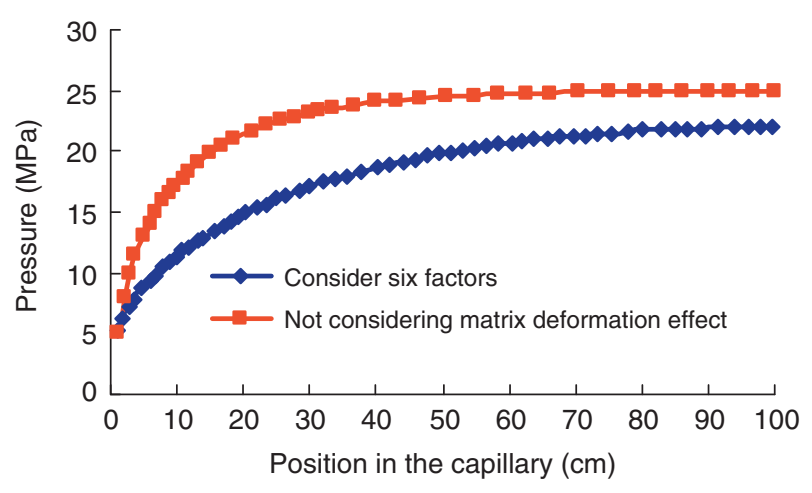

Figure 4

Capillary pressure distribution under not considering matrix deformation effect.

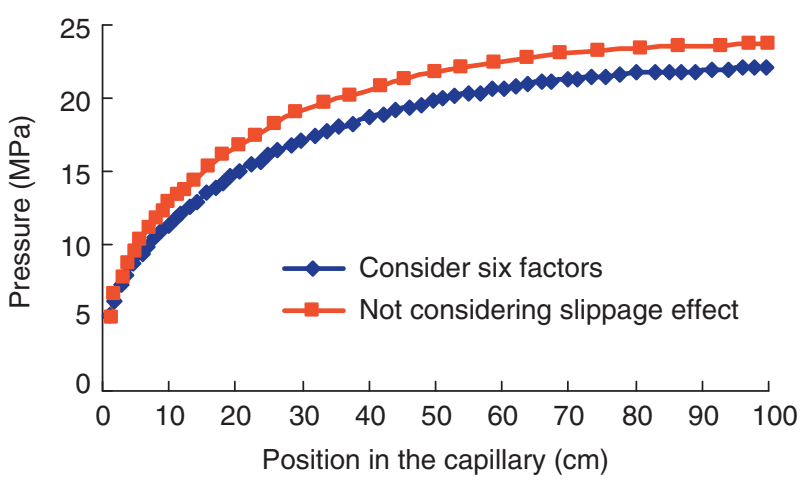

Figure 5

Capillary pressure distribution under not considering slippage effect.

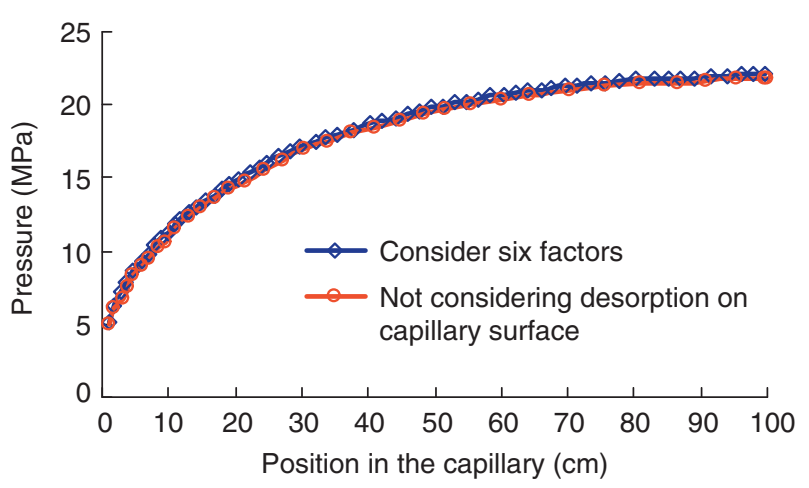

Figure 6

Capillary pressure distribution under not considering desorption on capillary surface. boundary is $25 \mathrm{MPa}$ when not considering the matrix deformation effect. On the same curve, the pressure is 24.5 $\mathrm{MPa}$ at the $50 \mathrm{~cm}$ point, and the pressure is $20 \mathrm{MPa}$ at $16 \mathrm{~cm}$ point. The nano pore diameter is fixed in the whole simulation process if the matrix deformation effect is not considered. Compared with considering overall factors, the nano pore diameter can be assumed to become narrower when ignoring the matrix deformation effect. The pressure transmission is slow, the pressure consumption increases near the well bore.

Figure 5 shows the pressure contrast with one curve considering all factors, and the other one not considering the slippage effect. At the initial state, the pressure that does not consider slippage effect is higher than the pressure considering all factors, with pressure values of 23.64 and $21.93 \mathrm{MPa}$, respectively. This means that the slippage effect is an important factor in shale gas production, and should not be ignored. When slippage effect is not considered, the pressure is $21.6 \mathrm{MPa}$ at the $50 \mathrm{~cm}$ point, and $16.35 \mathrm{MPa}$ at the $16 \mathrm{~cm}$ point. When calculating the slippage effect, the value of the gas slippage correction factor becomes larger as pressure decreases. Compared with the pressure that considers all factors, the flow ability in the capillaries reduces if the slippage effect is not considered. The pressure decrease mainly occurs near the well bore.

Figure 6 shows the pressure variation with one curve considering all factors, and the other one not considering desorption on the capillary surface. At the initial state, the pressure not considering desorption on capillary surface is slightly less than the pressure considering all factors, with pressure values at 21.93 and $21.91 \mathrm{MPa}$, respectively. When desorption on capillary surface is not considered, the pressure is $19.7 \mathrm{MPa}$ at the $50 \mathrm{~cm}$ point, and $13.5 \mathrm{MPa}$ at the $16 \mathrm{~cm}$ point. The adsorbed gas desorbs from the capillary surface, flowing into the 


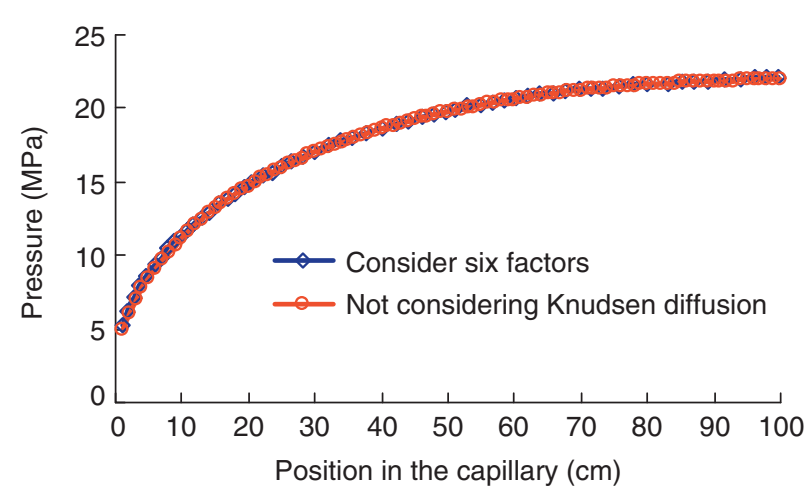

Figure 7

Capillary pressure distribution under not considering desorption on capillary surface.

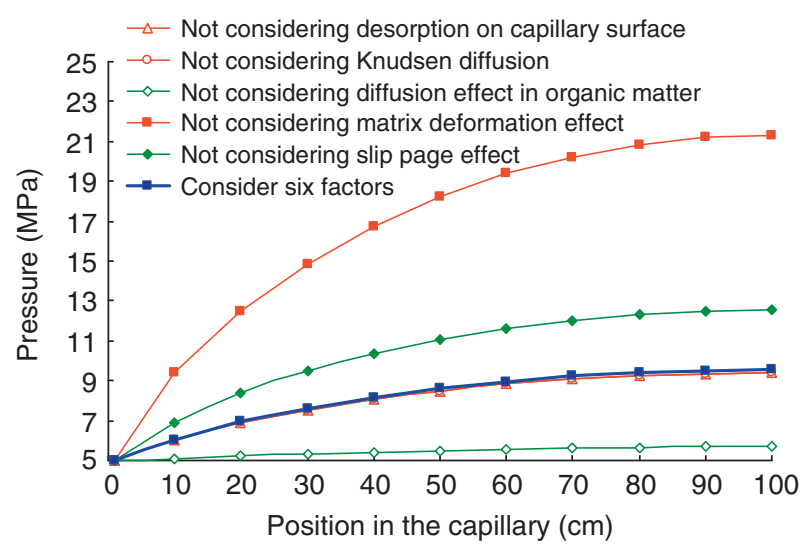

Figure 8

Capillary pressure distribution under different influence factors after a certain time.

capillary string, and the desorption gas interferes with the capillary gas, thus influencing the gas flowing although the influence is not obvious because the quantity of gas adsorbed is low.

Figure 7 shows the pressure variation with one curve considering all factors, and the other one not considering Knudsen diffusion. Knudsen diffusion increases the mobility of gas molecules, but the influence is not obvious because the velocity of the Knudsen diffusion is very slow at the beginning of production. At the same time, the velocity of gas diffusion is also very slow, so the amount of gas diffusing from the organic matter to the capillary strings is tiny and it has no obvious effect on the pressure.
Figure 8 shows the pressure distribution in the capillary under the action of various factors with the simulation time increasing by 10 times. The pressure has changed dramatically after a certain production time.

With the production time increasing by a factor 10 , the desorption on the capillary surface and the Knudsen diffusion have a more obvious effect on the pressure than the original condition. However, the other three factors have more influence on the pressure. The closed boundary pressure is $21.26 \mathrm{MPa}$ without considering the matrix deformation effect. The pressure is $12.52 \mathrm{MPa}$ without considering slippage effect. If we do not consider the diffusion effect in organic matter, the pressure is 5.69 $\mathrm{MPa}$. The pressure is $9.55 \mathrm{MPa}$ when considering six factors. The gas in the organic matter continuously diffuses into the capillary with the increasing of production time. The gas diffusion from organic matter helps to maintain the pressure, and the pressure drop becomes slow because of the gas diffusion.

\section{CONCLUSIONS}

In this study, we establish a capillary model to simplify the shale gas flow development process. Six factors of influence are studied to analyze the mechanism of shale gas flow in capillaries. Our shale gas pseudo twodimensional unsteady capillary seepage mathematical model establishes a mechanism for the analysis of shale gas flow, solved by the implicit difference method. Our simulation results show that the Knudsen diffusion effect and desorption of gas on capillary surfaces has less impact on pressure than the other factors. The diffusion effect of gas in organic matter, the slippage effect and the matrix deformation effect have greater impact on the pressure. The gas diffusion from organic matter helps to maintain the pressure.

\section{ACKNOWLEDGMENTS}

This research is supported by the Fundamental Research Funds of the Central Universities, and the National Special Fund (No. 2011ZX05009-006).

\section{REFERENCES}

Bear J. (1972) Dynamics of Fluids in Porous Media, Dover Publications, Inc., New York.

Brown G.P., Dinardo A., Cheng G.K., Sherwood T.K. (1946) The Flow of Gases in Pipes at Low Pressures, Journal of Applied Physics 17, 10, 802-813. 
Clarkson C.R., Nobakht M., Kaviani D., Ertekin T. (2012) Production Analysis of Tight Gas and Shale Gas Reservoirs Using the Dynamic-Slippage Concept, SPE Journal 17, 1, 230-242.

Curtis J.B. (2002) Fractured shale-gas system, AAPG Bulletin 86, 11, 1921-1938.

Ertekin T., King G.A., Schwerer F.C. (1986) Dynamic Gas Slippage: A Unique Dual-Mechanism Approach to the Flow of Gas in Tight Formations, SPE Formation Evaluation 1, 1, 43-52.

Hartman R.C., Ambrose.R.J., Akkutlu I.Y., Clarkson C.R. (2011) Shale Gas-in-Place Calculations Part II - Multicomponent Gas Adsorption Effects, North American Unconventional Gas Conference and Exhibition, Texas, USA, 14-16 June.

Javadpour F. (2009) Nanopores and Apparent Permeability of Gas Flow in Mudrocks (Shales and Siltstone), Journal of Canadian Petroleum Technology 48, 8, 16-21.

Kanellopoulos N.K. (1985) Capillary models for porous media: Newtonian and non-Newtonian flow, Journal of Colloid and Interface Science 108, 1, 11-17.

Kerkhof P.J.A.M., Geboers M.A.M. (2005) Analysis and extension of the theory of multi-component fluid diffusion, Chemical Engineering Science 60, 12, 3129-3167.

Letham E.A. (2011) Matrix Permeability Measurements of Gas Shales: Gas Slippage and Adsorption as Sources of Systematic Error, Bachelor Thesis, The University of British Columbia.

Loucks R.G., Reed R.M., Ruppel S.C., Hammes U. (2012) Spectrum of pore types and networks in mudrocks and a descriptive classification for matrix-related mudrock pores, AAPG Bulletin 96, 6, 1071-1098.

Malek K., Coppens M.O. (2003) Knudsen self- and Fickian Diffusion in Rough Nanoporous Media, Journal of Chemical Physics 119, 5, 2801-2811.
Markovic A., Stoltenberg D., Enke D., Schlnder E.U., SeidelMorgenstern A. (2009) Gas permeation through porous glass membranes Part I. Mesoporous glasses-Effect of pore diameter and surface properties, Journal of Membrane Science 336, 1-2, 17-31.

Muskat M., (1946) The Flow of Homogeneous Fluids through Porous Media, Edwards J.W., Inc. Ann Arbor, Michigan.

Ozkan E., Raghavan R., Apaydin O.G. (2010) Modeling of Fluid Transfer From Shale Matrix to Fracture Network, SPE Annual Technical Conference and Exhibition, Florence, Italy, 19-22 Sept.

Scheidegger A.E. (1957) The physics of flow through porous media, University of Toronto Press, Toronto.

Shabro V., Torres-Verdin C., Javadpour F. (2011) Numerical Simulation of Shale-Gas Production: from Pore-Scale Modeling of Slip-Flow, Knudsen Diffusion, and Langmuir Desorption to Reservoir Modeling of Compressible Fluid, North American Unconventional Gas Conference and Exhibition, Texas, USA, 14-16 June.

Swami V. (2012) Shale Gas Reservoir Modeling: From Nanopores to Laboratory, SPE Annual Technical Conference and Exhibition, Texas, USA, 8-10 Oct.

Swami V., Settari A.T. (2012) A Pore Scale Gas Flow Model for Shale Gas Reservoir, SPE Americas Unconventional Resources Conference, Pennsylvania, USA, 5-7 June.

Yao T.Y., Huang Y.Z., Li J.S. (2012) Flow Regim for Shale Gas in Extra Low Permeability Porous Media, Chinese Journal of Theoretical and Applied Mechanics 44, 6, 990-995.

Manuscript accepted in February 2014 Published online in May 2014 